\title{
Cigarette Manufacturing and Quality of Life in Women Workers
}

\author{
Marselius Sampe Tondok, Yosie Yurida Aliyono, Ayuni - University of Surabaya \\ marseliustondok@yahoo.com
}

The tobacco industry is still the top contributor to Indonesia's state tax. PT " $\mathrm{X}$ " is the largest cigarette company in Indonesia, which some of its factories are located in Surabaya. The workers of PT "X" are dominated by woman as production workers that considered to have special abilities to cigarette manufacture because of their characteristics of careful, conscientious, diligent, quick, skilled, and obedient. This study aims to describe the quality of life of women workers at PT "X".

The participants $(\mathrm{N}=150)$ were selected from production department by using snowball sampling technique. Data were collected by using the short version of the WHO Quality of Life Questionnaire (WHOQoL-Bref) consisting of 26 items to measure the physical, psychological, social relationships, and environment dimensions. Data are analyzed by descriptive quantitative: frequency distribution, and cross tabulation.

The results showed that the quality of life of the participant was classified as moderate and tend to be high. Quality of life of women workers at PT "X" were influenced by several external and internal factors. External factors consist of social comparison and the increasing of self-esteem obtained from the social environment. Meanwhile, the internal factors were more associated with their positive perception to their role in decision-making in the family because of their significant support to their family economy. Suggestions for further research are doing research on a smaller cigarette companies, and more focus on the quality of life of women workers in relation to fulfillment of their rights.

Keywords: Quality of life, women workers, social comparisons. 